\title{
CONHECIMENTOS TRADICIONAIS E O DIREITO EMPRESARIAL ÀS PATENTES
}

\section{TRADITIONAL KNOWLEDGE AND BUSINESS LAW}

\section{ANA CAROLINA LUCENA BRITO}

Graduada em Direito - Universidade do Estado do Amazonas (UEA). Discente especial do Programa de Mestrado em Ciências ambientais e Sustentabilidade na Amazônia, na UFAM - universidade Federal do amazonas. Manaus-AM. E-mail: carolinalucenab@gmail.com.

\section{ANDRÉ LUÍS FREGAPANI LEITE}

Mestrando em Direito Ambiental - PPGDA - Universidade do Estado do Amazonas (UEA). Manaus-AM. Especialista em Direito público E-mail: fregapanileite@gmail.com

\section{VALMIR CÉSAR POZZETTI}

Doutor em Direito Ambiental pela Univ. de Limoges/França; prof. Adjunto da Univ. do Estado do Amazonas e prof. Adjunto da Univ. Federal do Amazonas. E-mail: v_pozzetti@hotmail.com

\section{RESUMO}

O objetivo desta pesquisa foi o analisar a relação contratual que se forma entre as empresas de biotecnologia e os povos tradicionais, quando as primeiras utilizam-se dos conhecimentos dos segundos para reduzir custo e tempo gasto com pesquisas, obtendo lucro, sendo a devida remuneração aos povos tradicionais em virtude dos conhecimentos por eles oferecidos. Ressaltou-se a relevância jurídica da proteção do direito da propriedade intelectual e industrial, perpassando por uma análise da evolução histórica dos instrumentos jurídicos no cenário mundial, podendo-se citar a 


\section{Personalidade Acadêmica Homenageada:}

Raymundo Juliano Feitosa (Universidade Federal do Rio Grande do Norte - UFRN)

Convenção da União de Paris, em 1883, seguida da criação da Organização Mundial do Comércio através do Acordo de Marrakesh, em 1994, que teve como seu mais importante instrumento o TRIPS. O TRIPS é um marco pelo qual muitos países regularam suas normas internas acerca da propriedade intelectual, incluindo o Brasil que é consignatário no Acordo. Já no Brasil, este âmbito sofreu modificações após a Constituição Federal, de 1988, garantindo como direito fundamental a propriedade intelectual, até se obter a legislação vigente no país acerca do tema, a Lei oㅜ9.279/96. A lei por fim regulamentou o registro de patentes e as obrigações inerentes, dentre outras disposições. Sobre tais, destacam-se as patentes verdes que visam tutelar conhecimentos de inovação biotecnológica, a fim de propagar o desenvolvimento sustentável na produção industrial. Todavia, verificou-se que no ramo houve graves violações aos direitos dos povos indígenas e tradicionais, no momento que as empresas utilizavam seus conhecimentos milenares e os patenteavam como se donos fossem. Desse modo, após intensos debates e novas concepções, entendeu-se que tais saberes não podem ser objetos de patentes. Ao fim, concluiu-se que o programa "Patente Verde" pode concorrer para grandes avanços tecnológicos e econômicos no Brasil; mas deve sempre respeitar às diretrizes do desenvolvimento sustentável, no qual se encontram direitos sociais e ambientais, garantindo a razoabilidade dos direitos e assegurando a inviolabilidade dos mesmos.

PALAVRAS-CHAVES: Patentes; conhecimentos tradicionais; desenvolvimento sustentável.

\section{ABSTRACT}

The objective of this research is to analyze the contractual relationship that is formed between biotechnology companies and traditional peoples, when the former use the knowledge of the second to reduce cost and time spent with research, obtaining profit, due to the remuneration to the people their knowledge. The legal relevance of the protection of the right to intellectual and industrial property was emphasized, as well as an analysis of the historical evolution of the legal instruments on the world scene, 


\section{Personalidade Acadêmica Homenageada:}

Raymundo Juliano Feitosa (Universidade Federal do Rio Grande do Norte - UFRN)

including the Paris Convention of 1883 , followed by the creation of the World Organization through the Marrakesh Agreement in 1994, which had as its most important instrument TRIPS. TRIPS is a milestone for many countries to regulate their internal rules on intellectual property, including Brazil that is a signatory to the Agreement. In Brazil, this scope was modified after the Federal Constitution of 1988, to guarantee as fundamental right the intellectual property, until obtaining the legislation in force in the country on the subject, Law 9.279 / 96. The law finally regulated the registration of patents and the inherent obligations, among other provisions. These include green patents aimed at protecting knowledge of biotechnological innovation in order to promote sustainable development in industrial production. However, it was found that there were serious violations of the rights of indigenous and traditional peoples, as companies used their millennial knowledge and patented them as owners. Thus, after intense debates and new conceptions, it was understood that such knowledge can not be objects of patents. Finally, it was concluded that the green patent program can contribute to major technological and economic advances in Brazil, but should always respect the guidelines of sustainable development, which include social and environmental rights, guaranteeing the reasonableness of rights and ensuring the their inviolability.

KEYWORDS: Patents; traditional knowledge; sustainable development.

\section{INTRODUÇÃO}

Os conhecimentos tradicionais, aqueles passados de gerações à gerações, entre os povos tradicionais (indígenas, ribeirinhos, quilombolas,...) constitui um patrimônio invisível, que foi conquistado ao longo dos anos, com a sabedoria popular e experimentações. Os saberes sobre como utilizar um determinado animal ou vegetal, para curar males ou utilização como cosméticos, é de domínio dos povos tradicionais, da floresta, que convivem com essa fauna e flora, ao longo de centenas de anos. 


\section{Personalidade Acadêmica Homenageada:}

\section{Raymundo Juliano Feitosa (Universidade Federal do Rio Grande do Norte - UFRN)}

Por outro lado, ao conferir status constitucional à proteção da propriedade intelectual, o Brasil cada vez mais tem incentivado a prática de pesquisas ou produção industrial na iniciativa privada, garantindo seus direitos e obrigações através das chamadas patentes dos seus conhecimentos e marcas com valores econômicos.

Todavia, dentre o ramo da Biotecnologia, as empresas, contemporaneamente, tem promovido uma aproximação com esses povos e tem usurpado esses conhecimentos, o que tem Ihes permitido economizar anos de pesquisa e recursos financeiros de grande monta.

Dessa forma, o objetivo dessa pesquisa é o de verificar se a legislação pátria protege o direito dos povos tradicionais, no tocante ao uso desses conhecimentos, pelas empresas de biotecnologia.

Durante muitos anos os conhecimentos tradicionais associados à manipulação de patrimônio genético vêm sendo utilizados por empresas de biotecnologia e pesquisadores para aprimorar o conhecimento científico e, assim, serem empregados na produção de novos produtos. Dessa forma, a utilização desses conhecimentos pelas Empresas de Biotecnologia acelera o conhecimento das propriedades e princípios ativos que plantas e animais silvestres possuem, economizando tempo e dinheiro.

Assim, diante de tal cenário, a problemática que rege a presente pesquisa é: de que maneira as "patentes sustentáveis" favorecem o desenvolvimento sustentável e incentivam as inovações tecnológicas ecológicas? E como compatibilizar os interesses patentetários e os direitos socioambientais de comunidades indígenas e tradicionais em conflitos no acesso ao patrimônio genético e conhecimentos tradicionais associados?

A pesquisa se justifica tendo em vista que essa tem sido uma prática comum de empresas multinacionais que se apropriam, desse conhecimento, caracterizando a "biopirataria", o que prejudica não só os povos tradicionais, mas também a economia do Brasil, que perde quando um novo produto é lançado no mercado, com patentes internacionais, oriundas de conhecimentos dos povos da floresta.

Logo, o objetivo da presente pesquisa é analisar o ordenamento jurídico vigente sobre patentes e conhecimentos tradicionais associados e verificar 
Personalidade Acadêmica Homenageada:

Raymundo Juliano Feitosa (Universidade Federal do Rio Grande do Norte - UFRN)

razoavelmente como promover a proteção do direito patentetário e o direito dos povos indígenas e tradicionais.

\section{METODOLOGIA UTILIZADA}

Os métodos de pesquisa são um conjunto de procedimentos sistemáticos utilizados na elaboração de conhecimento acerca de um fenômeno-objeto. São eles que estabelecem o caminho da pesquisa. O método dedutivo parte de uma verdade geral para provar um fato particular. Sobre o tema relacionado com a proposta de pesquisa, o método dedutivo é o mais pertinente, conforme preleciona Marconi e Lakatos (2010, p. 23): "[...] partindo das teorias e leis, na maioria das vezes prediz a ocorrência dos fenômenos particulares".

Em relação ao tipo de pesquisa previsto neste resumo, a pesquisa qualitativa torna-se mais pertinente se o objeto do assunto for considerado. A respeito da pesquisa qualitativa, Oliveira (2007, p. 41) diz que ela: "tem um processo de reflexão e análise da realidade através da utilização de métodos e técnicas para compreensão detalhada do objeto de estudo em seu contexto histórico e/ou segundo sua estruturação". Quanto aos meios utilizados para coletar dados para se chegar à conclusão da pesquisa, a bibliográfica se adequa perfeitamente, devido sua realização ser com base em material publicado em livros, jornais, revistas, sites na internet, e que sejam disponibilizados ao público em geral.

Por fim, conclui-se que a pesquisa científica em análise adotará como método o dedutivo, combinado com pesquisa bibliográfica e qualitativa com uso da legislação, doutrina e jurisprudência. 
Personalidade Acadêmica Homenageada:

Raymundo Juliano Feitosa (Universidade Federal do Rio Grande do Norte - UFRN)

\title{
DESENVOLVIMENTO
}

\section{A ORIGEM DAS PATENTES}

O conjunto de categorias denominado propriedade intelectual compreende referencialmente os bens imateriais da propriedade do empresário, sendo estes: patentes, marcas ou nomes empresariais. O direito patentetário, ligado à propriedade industrial, surgiu como um mecanismo de proteção da imaterialidade da propriedade intelectual.

Segundo Pozzetti e Mendes (2014, p. 211):

\begin{abstract}
Durante 63 anos, a borracha gerou muita riqueza e se expandiu para o mercado de todo o mundo. Segundo Jackson (2011, p. 13), "o vale amazônico dominou o mercado mundial da borracha, mas depois a bolha se rompeu, pois suas sementes foram pirateadas, e em apenas um ano, o ciclo da borracha se converteu em um fracasso". O Brasil subestimou a cobiça estrangeira, e, em 1913, com a ausência de leis protetivas, tivemos o primeiro ataque dos biopiratas: 70 mil sementes foram contrabandeadas do Brasil e levadas para plantações na Malásia, que, cultivadas em terreno adequado e de fácil acesso, permitia a produção em larga escala e a inserção do produto no mercado consumidor, com mais facilidade e menor preço e, em pouco tempo, a borracha cultivada na Malásia substituiu a borracha "selvagem da Amazônia" no mercado mundial, com um preço mais baixo, pois a coleta e o transporte eram menos onerosos que a borracha produzida no Amazonas.
\end{abstract}

Originalmente, até século XIX, período da Revolução Industrial, não existia uma legislação apropriada que regulamentassem as patentes, sendo aplicada, muitas vezes, a legislação de um país em outro. Enfim, em 1883, um grande passo foi dado, resultado da progressão da internacionalização do comércio intelectual, que foi a edição da Convenção da União de Paris (CUP).

Nesse sentido Sabino (2007, p. 47) esclarece que:

Por ser o primeiro acordo internacional referente à propriedade industrial, o Acordo de Paris estabeleceu regras extremamente simples e gerais dando flexibilidade aos países membros para conduzir seus sistemas de propriedade industrial por meio de suas legislações locais. Tem-se, assim, a liberdade para criar um regime próprio de propriedade intelectual, tendo em vista as especificidades do país. A Convenção da União de Paris - CUP, de 1883, deu origem ao hoje denominado Sistema Internacional da Propriedade 
Personalidade Acadêmica Homenageada:

Raymundo Juliano Feitosa (Universidade Federal do Rio Grande do Norte - UFRN)

Industrial e foi a primeira tentativa de uma harmonização internacional dos diferentes sistemas jurídicos nacionais relativos à propriedade industrial.

Outro importante marco no que concerne à propriedade intelectual foi a criação da Organização Mundial do Comércio através do Acordo de Marrakesh, em 15 de abril de 1994, entrando em vigor em 1ํ de janeiro de 1995. A OMC é uma organização multilateral, internacional e independente, para construção, defesa e desenvolvimento do sistema mundial do comércio, possuindo como um de seus principais instrumentos o Acordo sobre Aspectos dos Direitos de Propriedade Intelectual relacionados ao Comércio (ADPIC - TRIPS), pelo qual surgiu o sistema de patentes que vigora atualmente nos países consignatários do acordo.

No Brasil, o TRIPS foi incorporado ao direito interno por intermédio do Decreto nำ 1.355, de 30 de dezembro de 1994, mais tarde fundamentando a Lei no 9.279, de 14 de maio de 1996, que regula direitos e obrigações relativos à propriedade industrial.

\title{
2 ORDENAMENTO JURÍDICO SOBRE PATENTES
}

O sistema jurídico de proteção da propriedade intelectual passou por grande evolução no cenário mundial, influenciando fortemente os ordenamentos internos de cada país. Assim também no Brasil, com a promulgação da Constituição Federal de 1988, o direito patentetário ganhou eficácia constitucional de direito fundamental:

\begin{abstract}
Art. 5ำ Todos são iguais perante a lei, sem distinção de qualquer natureza, garantindo-se aos brasileiros e aos estrangeiros residentes no País a inviolabilidade do direito à vida, à liberdade, à igualdade, à segurança e à propriedade, nos termos seguintes: [...] omissis XXIX - a lei assegurará aos autores de inventos industriais privilégio temporário para sua utilização, bem como proteção às criações industriais, à propriedade das marcas, aos nomes de empresas e a outros signos distintivos, tendo em vista o interesse social e o desenvolvimento tecnológico e econômico do País;
\end{abstract}

Nesse sentido, Pozzetti e Mendes (2014, p. 220) destacam:

Dessa forma, percebe-se que os bens ambientais primários possuem um valor inestimável à indústria de transformação; logo, possuem valor 
Personalidade Acadêmica Homenageada:

Raymundo Juliano Feitosa (Universidade Federal do Rio Grande do Norte - UFRN)

econômico, e o uso desses recursos, ou a utilização desses pela indústria de transformação, deve ser remunerado em benefício da coletividade, que contribui para que haja a oferta desse bem ambiental.

Dessa maneira, a Lei das Patentes brasileira (Lei $n^{\circ}$ 9.279/96), que regulamenta os acordos internacionais, os quais o Brasil é parte, bem como o disposto no texto constitucional, visa proteger a propriedade intelectual através da concessão de patentes de invenção e de modelo de utilidade, registro de marcas e desenhos industriais, além de regulação de outros direitos e obrigações.

Uma grande inovação da referida lei foi a inclusão da patente para substâncias, matérias ou produtos obtidos por meio de processos químicos e as substâncias, produtos alimentícios, químico-farmacêuticos e medicamentos de qualquer espécie, assim como os respectivos processos de obtenção e modificação, conforme se observa no dispositivo da lei:

Art. 230. Poderá ser depositado pedido de patente relativo às substâncias, matérias ou produtos obtidos por meios ou processos químicos e as substâncias, matérias, misturas ou produtos alimentícios, químicofarmacêuticos e medicamentos de qualquer espécie, bem como os respectivos processos de obtenção ou modificação, por quem tenha proteção garantida em tratado ou convenção em vigor no Brasil, ficando assegurada a data do primeiro depósito no exterior, desde que seu objeto não tenha sido colocado em qualquer mercado, por iniciativa direta do titular ou por terceiro com seu consentimento, nem tenham sido realizados, por terceiros, no País, sérios e efetivos preparativos para a exploração do objeto do pedido ou da patente.

Dentre o avanço da biotecnologia, descobriu-se que os conhecimentos tradicionais e milenares praticados por comunidades indígenas e tradicionais poderiam servir para aplicação em produtos industriais e farmacêuticos e gerar grande avanço econômico e tecnológico.

Com isso surgiu uma prática comum entre as empresas desse segmento em se aproximarem de comunidades indígenas e tradicionais e utilizarem os conhecimentos adquiridos por seus antepassados sobre o manuseio de recursos genéticos e, assim, poupar um longo tempo de pesquisa, principalmente para fabricação de produtos com base vegetal e animal, e, assim usurpavam a patente dessa espécie de conhecimento, tornando-se seus proprietários. 
Personalidade Acadêmica Homenageada:

Raymundo Juliano Feitosa (Universidade Federal do Rio Grande do Norte - UFRN)

Desse modo, a partir do século XX, passou-se a ser discuta a questão, por serem esses saberes tão relevantes, não só para a cultura de seus detentores, mas também para a exploração dos recursos genéticos para ciência e tecnologia no Brasil que, inclusive, possui vasto domínio deles. Porém, questionou-se perante a comunidade ambientalista: afinal, estes conhecimentos são passíveis de serem patenteados?

\section{CONHECIMENTOS TRADICIONAIS: POSSÍVEL DE PATENTES?}

Um dos aspectos de grande magnitude em que se insere no assunto é quanto ao acesso a recursos genéticos e conhecimentos tradicionais associados pelas empresas. A importância da tutela desses elementos pelo Direito se dá pelo o que eles representam na preservação das raízes históricas e culturais de grupos indígenas e comunidades tradicionais (ribeirinhos, caboclos, quilombolas, etc...) que habitam o território brasileiro, pois os saberes tradicionais perpassados de geração a geração constituem um patrimônio que ao longo dos anos foi vulneravelmente violado em muitos casos.

Naquele momento anterior, ainda não se enxergava os conhecimentos tradicionais por concepções que se tem hoje no meio jurídico, o que se passou a carecer de um regime normativo em que fossem protegidos de acordo com sua qualificação. Nesse sentido Brito e Pozzetti $(2017$, p. 6) esclarecem que:

\footnotetext{
No pretérito, concebia-se que conhecimento tradicional era tido como propriedade intelectual e, assim, passível de patenteamento, algo que ocorria comumente. $O$ empresário se aproximava da comunidade para adquirir seus conhecimentos e os patenteava, tornando-o "proprietário" destes. Ocorre que conhecimento tradicional vai além de algo intelectual. Representa cultura e emerge expressões de identificação de um povo; portanto, devendo ser protegido como tal.
}

Superando ideais retrógrados e que não coadunam com o que assevera os tratados internacionais sobre povos indígenas, a corrente majoritária atual defende que conhecimentos tradicionais associados pertencem ao Patrimônio Cultural e 
Personalidade Acadêmica Homenageada:

Raymundo Juliano Feitosa (Universidade Federal do Rio Grande do Norte - UFRN)

Direitos Humanos Culturais, como bem afirma Dantas (2006, p. 92) que "os conhecimentos tradicionais indígenas associados ao patrimônio genético configuram direitos coletivos de cada povo, são direitos culturais. Como tais, são protegidos constitucionalmente pela ordem jurídica brasileira e pelo conjunto integrado dos direitos humanos".

Assim, seguindo tais concepções, foi promulgada a Lei $n^{0}$ 13.123/2015, que regulamenta a matéria no Brasil. No corpo da lei, observa-se que, no que tange ao "conhecimento tradicional associado", a lei acaba por considerar em seu artigo $8^{\circ}$, parágrafo $2^{\circ}$, que "conhecimento tradicional associado ao patrimônio genético é um bem do patrimônio cultural brasileiro", pondo fim ao antigo tratamento que incluía os saberes tradicionais no sistema de patentes.

Vale destacar que, de acordo com a Convenção da Diversidade Biológica, de 1992, e o Protocolo sobre Acesso a Recursos Genéticos e a Repartição Justa e Equitativa dos Benefícios Advindos de sua Utilização, de 2010, a lei também prevê que este acesso deve ser realizado mediante a consulta prévia e consentimento livre, prévio e informado dos seus reais detentores, além de promover uma repartição justa e equitativa de benefícios oriundos dos lucros do produto final acabado, sendo de forma monetária ou não monetária.

\section{A EFICÁCIA DAS PATENTES PARA O MEIO AMBIENTE}

Por outro lado, apesar de não serem patenteáveis, os conhecimentos tradicionais associados, ainda existem espécies de patentes que visam a promoção do desenvolvimento sustentável através da inovação tecnológica relacionadas ao meio ambiente. Por isso, o que vem a se discutir é acerca da importância das patentes verdes para a disseminação e uso da nova tecnologia, como também seus efeitos sobre a sustentabilidade.

O Programa "Patente Verde" foi implantado pelo Instituto Nacional da Propriedade Industrial - INPI, em abril de 2012, a fim de que o exame de pedidos de patentes, que contemplem inovações relacionadas ao meio ambiente, sejam feitos de 


\section{Personalidade Acadêmica Homenageada:}

Raymundo Juliano Feitosa (Universidade Federal do Rio Grande do Norte - UFRN)

modo mais rápido em relação ao demais, mas também de identificar novas tecnologias para o desenvolvimento sustentável, que nesse contexto se inserem as pesquisas biotecnológicas de acesso ao patrimônio genético.

Vale salientar que os direitos ambientais e sociais integram as garantias constitucionais, conforme artigo 5ำ, LXXIII, artigo 6ำ e artigo 225, permeando ainda 0 capítulo da ordem econômica e financeira, artigos 170 e seguintes, da Constituição Federal.

Destarte, observando a patente sob a ótica do incentivo à inovação e retorno do investimento realizado, Richter (2014, p. 395) esclarece que:

[...] as patentes cumprem sem dúvida, um papel importante, pois possibilitam o retorno do investimento realizado na inovação por meio de licenças. Além disso, a proteção patentetária possibilita a reunião e sistematização de tais tecnologias por meio de indexadores que facilitam sua identificação via mecanismos de busca. Além disso, a patente confere o poder de instigar a concorrência para a inovação e pesquisas que tem de contornar a engenhosidade do objeto protegido, pois a identificação de um processo ou produto novo disponibilizado no mercado gera uma vantagem competitiva a ser considerada pela concorrência.

Por outro lado, deve-se sempre considerar a função social e ambiental que as patentes verdes devem exercer para um verdadeiro desenvolvimento sustentável, pelo qual também se delimita pelos princípios da bioética no seu manejo. Por esta razão, ao se utilizar inovações ambientais nas produções industriais biotecnológicas, principalmente em relação à conhecimentos tradicionais como já destacado, a patente verde não poderá sopesar o valor econômico em detrimento do social e cultural.

Sobre sustentabilidade e proteção dos direitos socioambientais dos povos indígenas e tradicionais, contribuem Brito e Pozzetti (2017, p. 8-9):

[...] o desenvolvimento deve estar atrelado à sustentabilidade a fim de garantir a qualidade de vida de todos os seres e efetivar o direito constitucional dos brasileiros a um meio ambiente ecologicamente equilibrado, não sendo motivo para atraso econômico, mas sim parte integrante de seu progresso. [...] Por outro lado, tem-se a proteção dos conhecimentos tradicionais das populações tradicionais e o reconhecimento de seus direitos. Essas populações pertencem ao grupo mais vulnerável do assunto em comento e por isso merecem consideração no que diz respeito à elaboração de normas, sendo elas diretamente afetadas. Os conhecimentos tradicionais, associados ao manejo de patrimônio genético, podem proporcionar grandes avanços 


\section{Personalidade Acadêmica Homenageada:}

Raymundo Juliano Feitosa (Universidade Federal do Rio Grande do Norte - UFRN)

tecnológicos na criação de fármacos e outros produtos fabricados que se utilizam desses. Ou seja, o seu usufruto representaria um elemento essencial ao desenvolvimento do país. No entanto, o acesso a esses conhecimentos não se pode dar de maneira abrupta, é preciso protegê-los.

Portanto, as patentes podem contribuir positivamente para a proteção ambiental, promovendo inovação tecnológica, avanço econômico e maior visibilidade para produtos ecológicos. Todavia, a patente verde deve sempre estar entrelaçada aos fundamentos sociais, nos quais se baseiam um eficaz desenvolvimento sustentável.

\section{CONSIDERAÇÕES FINAIS}

A problemática apresentada foi de que forma as patentes verdes contribuem para a sustentabilidade e de que maneira se devem compatibilizar os interesses patentetários e os direitos socioambientais de comunidades indígenas e tradicionais.

Os objetivos foram cumpridos à medida em que se analisou o ordenamento jurídico vigente sobre patentes e conhecimentos tradicionais e se pode verificar se ambos têm cumprido com o aclamado e comentado desenvolvimento sustentável, perseguido por todos.

Desse modo, verificou-se que o sistema de patentes é oriundo de mudanças no cenário do comércio mundial ao longo do tempo, tendo por seus principais marcos a Convenção da União de Paris, em 1883, seguida da criação da Organização Mundial do Comércio através do Acordo de Marrakesh, em 1994, que teve como seu mais importante instrumento o TRIPS, pelo qual muitos países regularam suas normas internas acerca da propriedade intelectual.

Verificou-se que, com a Constituição Federal, a proteção à propriedade intelectual ganhou notoriedade ao ser prevista como um direito fundamental e que em 1996 o ordenamento jurídico pátrio ganhou uma legislação específica, a Lei № 9.279/96. Foi por intermédio dessa lei que a propriedade intelectual e industrial 
Personalidade Acadêmica Homenageada:

Raymundo Juliano Feitosa (Universidade Federal do Rio Grande do Norte - UFRN)

começou a ser efetivamente tutelada e regulamentada, com destaque às patentes que envolve inovação ambiental e biotecnológica.

Todavia, observou-se que, ocorrendo preteritamente a prática de usurpação de saberes tradicionais de comunidades indígenas e tradicionais, atualmente vigora a teoria de que tais conhecimentos não são passíveis de patenteamento, por serem considerados Patrimônio Cultural de Direitos Humanos, portanto, seu acesso deve seguir todos os moldes previstos na Lei n⿳0 13.123/2015.

Por fim, concluiu-se que a patente verde pode concorrer para grandes avanços tecnológicos e econômicos no Brasil, desde que presente o respeito às diretrizes do desenvolvimento sustentável, no qual se encontram direitos sociais e ambientais que precisam ser sempre observados, à luz da razoabilidade.

\section{REFERÊNCIAS}

BRASIL. Constituição da República Federativa do Brasil. Brasília: Senado Federal, 1988.

. Lei no 9.279, de 14 de maio de 1996. Brasília: Congresso Nacional, 1996.

. Lei no 13.123, de 20 de maio de 2015. Brasília: Congresso Nacional, 2015.

BRITO, Ana Carolina Lucena; POZZETTI, Valmir César. Biodiversidade, conhecimentos tradicionais associados e repartição de benefícios. Lima: Derecho y Cambio Social, 2017. Disponível em: https://www.derechoycambiosocial.com/revista048/BIODIVERSIDADE.pdf. Acesso em 31 Mai 2019.

DANTAS, Fernando Antonio de Carvalho. Base jurídica para a proteção dos conhecimentos tradicionais. São Paulo: Revista CPC. v.1, n.2, p.80-95, maio/out. 2006.

MARCONI, Marina de Andrade. Fundamentos de Metodologia Científica. $7^{a}$ Edição. São Paulo: Atlas, 2010.

POZZETTI, Valmir César e MENDES, Máryka Lucy da Silva. Biopirataria na Amazônia e a ausência de proteção jurídica. Revista Direito Ambiental e sociedade , v. 4, n. 1, 2014 (p. 209-234). Disponível em www.ucs.br/etc/revistas/index.php/direitoambiental/article/download/3691/2114, consultada em 25 mai 2019. 
Personalidade Acadêmica Homenageada:

Raymundo Juliano Feitosa (Universidade Federal do Rio Grande do Norte - UFRN)

RICHTER, Fernanda Altvater. As patentes verdes e o desenvolvimento sustentável. Revista Meio Ambiente e Sustentabilidade, vol. 6, n.3, p. 383 - 398, jul - dez 2014. Disponível em: https://www.uninter.com/revistameioambiente/index.php/meioAmbiente/article/viewFil e/309/163. Acesso em 31 Mai 2019.

SABINO, Luciana Shicasho. Caracterização da proteção às patentes: estimulo do desenvolvimento econômico?. 2007. 181 f. Dissertação (Mestrado em Direito) Universidade Católica de Brasília, Brasília, 2007. Disponível em: https://bdtd.ucb.br:8443/jspui/handle/123456789/387. Acesso em 31 Mai 2019. 